\title{
Women in neurosurgery: a challenge to change history-Brazil, São Paulo
}

\author{
Nelci Zanon
}

Published online: 14 January 2011

(C) Springer-Verlag 2011

\section{In the world}

The history of women in the work force is one of very slow and small progresses, and it has not been different in medicine. The history of women in the professional world is changing over the centuries. Marie Curie was the first to use the term "radioactivity." Through her discovery of radium, Marie paved the way for nuclear physics and cancer therapy. She was the first woman in Europe to earn a doctorate degree (1902), the first woman to win a Nobel Prize, and she was the first person ever to receive two Nobel Prizes (Nobel Prize in Physics (1903) and Nobel Prize in Chemistry (1911)). Only ten women received the Nobel Prize in physiology and medicine to date. The first was Gerty T.R. Cori in 1947 and the last was Carol W. Greider, in 2009 "for the discovery of how chromosomes are protected by telomeres and the enzyme telomerase." The majority of them shared their prize with other scientists. The only woman to receive the prize individually was the geneticist Barbara McClintock in 1983 for the discovery of the jumping genes. In neurosurgery, the first woman to preside the Harvey Cushing Society (today's AANS) and edit the Journal of Neurosurgery was Luise Eisenhardt. In the medical business, we have a worldwide respected and admired, Madame Storz.

\footnotetext{
N. Zanon $(\triangle)$

CENEPE, Center of Pediatric Neurosurgery, Neuroendoscopy, and Congenital Malformations-Beneficencia Portuguesa Hospital, HBP,

Rua Capitão Mor Roque Barreto, $n^{\circ} 47$, Ground floor, CEP, 01323-030, Bairro Bela Vista,

São Paulo, São Paulo, Brazil

e-mail: dranelci@terra.com.br

URL: www.cenepe.com.br
}

\section{In Brazil}

Women were not allowed to attend medical school until 1879. The first female medical doctor in Brazil, Maria Augusta Generoso (from Rio de Janeiro) graduated in New York before returning to Brazil to practice medicine. Rita Lobato (from Rio Grande do Sul) was the first woman to study medicine in Brazil. She graduated in 1887 from the Medical School of Bahia. Over one century went by before Maria Irmã Seixas Duarte became the first professor at the Medical School of the University of São Paulo in 1997. São Paulo is the state of Brazil with the largest population, as well as the strongest economy. Last year, exports from São Paulo corresponded to a third of the total exports of Brazil. In 2010, the population of São Paulo state reached 42 million inhabitants, a number higher than 178 countries in the world and just below 29 other nations. The city of São Paulo alone exceeds 11 million inhabitants. The female population was $51.5 \%$ of the total, according to data from 2008.

\section{In neurosurgery}

The Brazilian Society of Neurosurgery (SBN) was created in 1957 with five members and the first woman to become a member of this society was Cleyde Cley da Silva Vescio in 1976, (database from SBN www.SBN.com.br). At that time, she represented $5.6 \%$ of all members (1/19). Since then the number of women practicing neurosurgery in Brazil has been increasing in numbers, but the ratio of man to woman is still the same. In 2009, from the 1,758 members of the SBN, only 97 were female, corresponding to the same $5.5 \%$ (Fig. 1). On the other hand, women are being admitted in increasing number at the medical schools. 


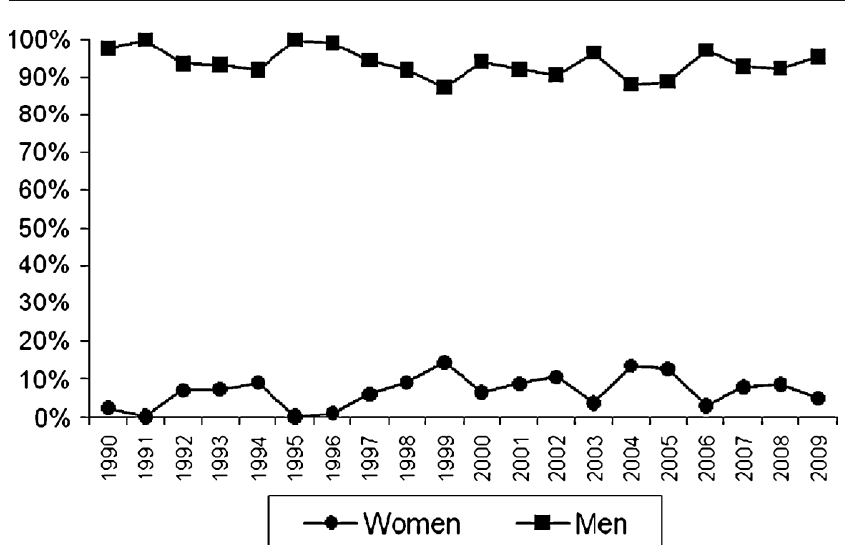

Fig. 1 The members of the Brazilian Society of Neurological Surgery over the last 10 years, percentage by gender

In São Paulo, new doctors registering at the Regional Council of Medicine in São Paulo/Brazil (CREMESP) are consolidating a trend: from the 3,029 graduates in medicine that registered in $2009,1,645(54 \%)$ were women and $1,384(46 \%)$ were men. Men represented $66.43 \%$ of new registrations in 1980. Twenty years later in 2000, male presence decreased, but men were still the majority, comprising $55.39 \%$ of new registrations. The inversion only happened in 2006 when women represented $51.75 \%$ of the 3,030 new registrations of the year. In 2007, women represented $52.78 \%$ and in 2008, 52.96\%. For the president of CREMESP, Luiz Alberto Bacheschi, in view of the fourth consecutive year of female predominance, the historic series points to a feminization of the medical profession in the state of São Paulo (www.cremesp.org.br).

\section{In neurosurgery}

Some questions arise from this information. Why are there so few female neurosurgeons despite an increase of graduating female doctors? Also, why hasn't the man to woman ratio changed in the last three decades? Is this an isolated fact or part of the secular lifestyle? This year, a new law in Brazil determines that a minimum of $30 \%$ of candidates for seats in the government be of each gender, but no politic party has achieved this goal. There is a saying that claims that if a woman decides to have one child a year, then her job will have to be performed by somebody else. Reality is somewhat different. Fertility is decreasing, even in Brazil. Ten years ago the mean number of children per woman was 2.5 children and now it is around 1.3 per woman. With medical schools tending to be more accessible to women and the decreasing fertility rate, the neurosurgical specialty could become another option for a medical career. This year there were four major candidates for president of Brazil, two of them being women. In October 31st, Brazilians elected the first woman president in our history. This fact, however, may not necessarily change the neurosurgical work force profile. There has been no trend toward any change in the man to woman ratio in neurosurgery in the last 10 years (Fig. 1). Interestingly, despite an unchanging gender division, the members of the SBN are getting younger over the last 10 years (Fig. 2). So, easier access to medical schools has not affected the decision of women to choose neurosurgery as a career. The next challenge will be to find ways to attract more women in this field.

\section{In São Paulo}

São Paulo hosts the largest private hospital in South America: Beneficência Portuguesa Hospital (BPH) managed by the Ermirio de Moraes family since 1951. It consists of six buildings (Fig. 3); 143,000 $\mathrm{m}^{2} ; 1,920$ beds; 64 operating rooms; and a tradition in neurosurgery and heart surgery. On average, 30 thousand surgeries are performed every year. In 2008, there were 7,851 (34\%) cardiac surgeries and 1,552 neurological surgeries. There is a big potential for increasing the number of neurosurgical procedures according to local redefinition in work strategies. In the year of the 151st anniversary of $\mathrm{BPH}$, the creation of a pediatric neurosurgery unit is an advance in the care provided for children with neurological problems who require neurosurgical intervention. The coincidence is the fact that all the neurosurgeons of the team are women (cover figure, Fig. 4). In the neurosurgery department at HBP, there are many prominent, internationally renowned figures who have been working for many decades. Although the hospital is a private institution, $60 \%$ of its clientele belongs to the poorer socioeconomic classes, insured by the government's Unified Healthcare System. To be able to provide the same quality of care to the poor as

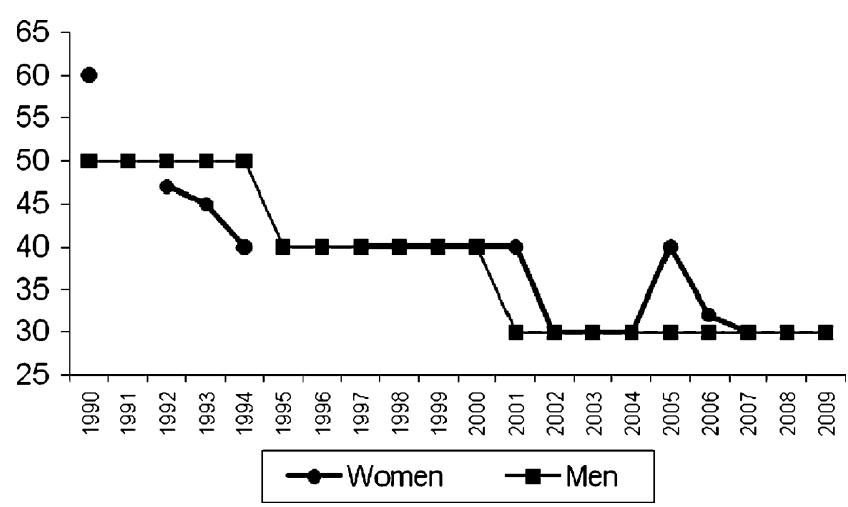

Fig. 2 The age of the members of the Brazilian Society of Neurological Surgery over the last 10 years, by age 


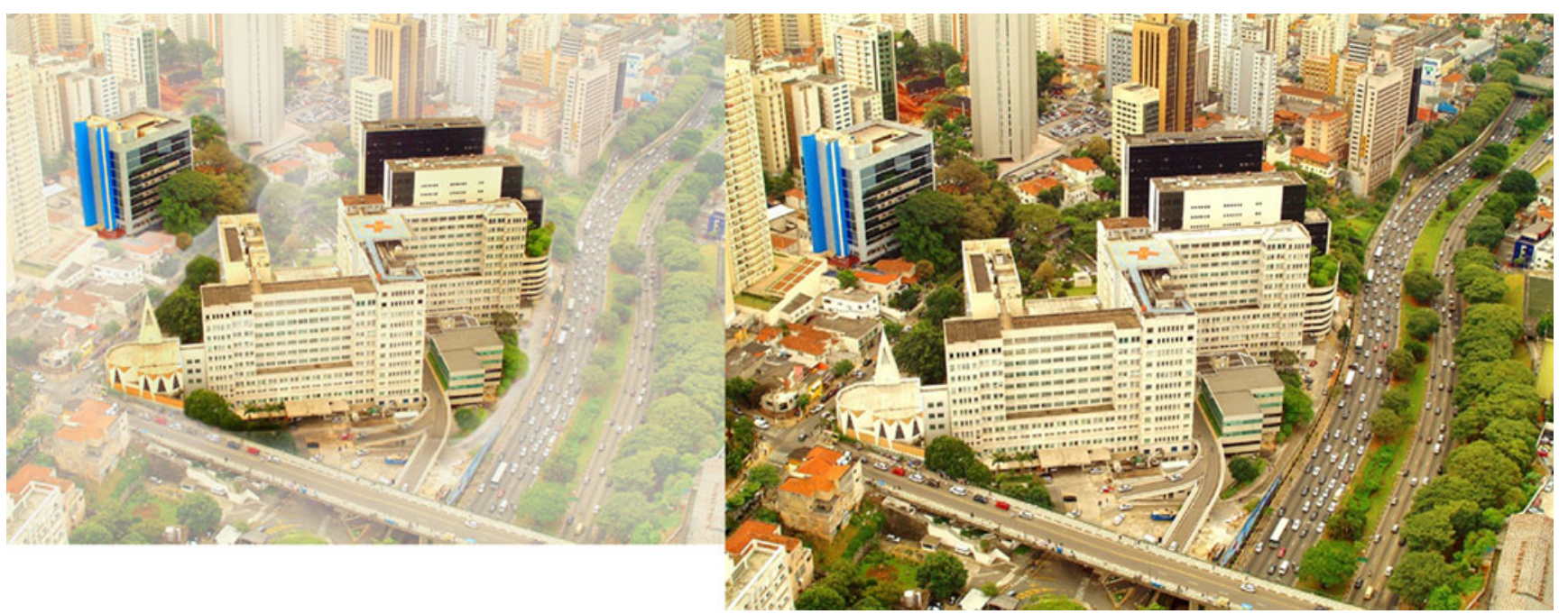

Fig. 3 The Beneficência Portuguesa Hospital, São Paulo, Brazil

it is given to those with private health insurance is a dream on the verge of becoming true. Perhaps one day we can celebrate the absence of waiting lists for elective surgeries for children who need neurosurgical procedures. Today there are still children - in the public healthcare system, with problems such as occult dysraphism, craniofacial deformities, and other malformations - who spend years waiting for elective surgery. Our team was born from a 15-year period dedicated to pediatric neurosurgery, working in São Paulo. We believe that pediatric neurosurgery is an interdisciplinary specialty and one of the essential characteristics of such team is the ability to add professionals that improve the results that are obtained to benefit the child, family, team, and the institution. It is quite an achievement to work for an institution that has dedicated 151 years of service to the community and is a reference in medical and hospital care for all segments of society. It is our goal to maintain reliability and excellence in the training of new professionals, focusing on the care provided for children with neurological problems and/or congenital malformations.

\section{In pediatric neurosurgery}

The Brazilian Pediatric Neurosurgery Society (www. sbnped.org), created in 1999, is a department of the Brazilian Society of Neurosurgery. Since then, we have pediatric neurosurgical meetings every 2 years. Since 2008, SBNPed had Child's Nervous System as the official journal of the society. Until now, we do not have the exact number of the members, we only perceive a number of women

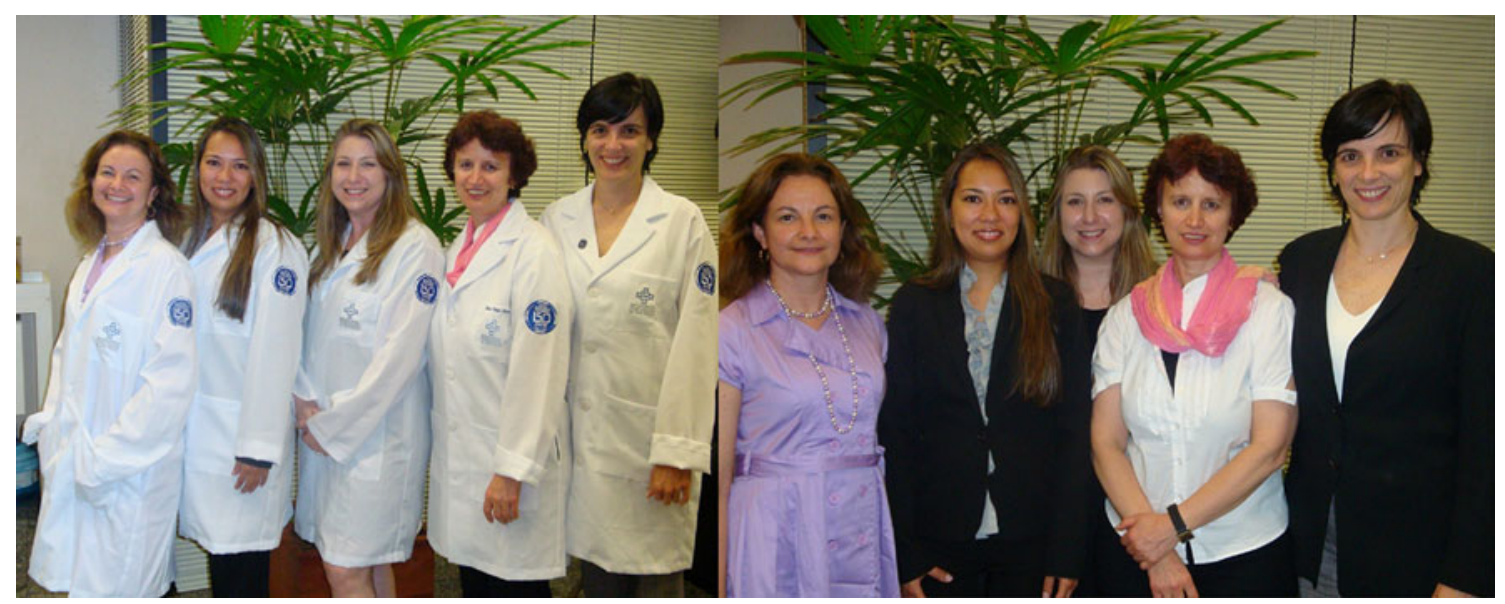

Fig. 4 The cover figure shows the Pediatric Neurosugical Team, CENEPE at the Beneficência Portuguesa Hospital, São Paulo, Brazil. Left to right, Silvana Brito and Márcia Noriko de Oliveira Homa, neurosurgeons; Maria Laura Alcântara, anesthesiologist; Nelci Zanon (head of department); and Rita Delgado Vilora, neurosurgeon 
more expressive in pediatric neurosurgical meetings when we compare spinal, vascular, or epilepsy meetings. The creation of a new neurosurgical team focused on pediatric neurosurgery and composed only of female pediatric neurosurgeons is an event to celebrate. As far as we know, there is no other neurosurgical team composed exclusively of women. We hope we may provide some sort of encourage- ment for other physicians to become neurosurgeons. Some years ago, Dr. Ezio Di Rocco, editor in chief of the ISPN journal Children's Nervous System said that if some day, some country were to have a female neurosurgery team, this country would probably be Brazil. At the time, this seemed like a very distant reality, but the circumstances made his prediction come true. 